\title{
La gobernanza global de la energía
}

\author{
Global energy governance
}

RECIBIDO: 23 DE MAYO DE 2016 /ACEPTADO: 30 DE JUNIO DE 2016

\section{Belén DEL RÍO}

Becaria de Investigación

Universidad del País Vasco

rosabelen.delrio@ehu.es

Resumen: La energía está ligada al desarrollo económico y la seguridad nacional. A menudo los gobiernos han entendido la energía como un área de la «alta política» donde los intereses nacionales predominan sobre los intereses colectivos. Sin embargo, la evolución del concepto de seguridad energética, la creciente conciencia de que es necesario mejorar el acceso a los servicios de energía modernos así como evitar un cambio climático peligroso, modificó esa aproximación hacia los problemas energéticos. La gobernanza energética global se ha convertido en el concepto de análisis de la colaboración internacional. Entender el concepto de gobernanza energética global precisa conocer la naturaleza y la magnitud del ámbito energético. Igualmente importante es conocer quién es el responsable de tomar las decisiones. Sólo entonces seremos capaces de tomar las medidas adecuadas. Este artículo se centra en analizar dos elementos: por qué la energía es un problema mundial y quién la gobierna.

Palabras clave: energía, gobernanza, seguridad energética, acceso a la energía, pobreza energética, clima y cambio climático

\begin{abstract}
Energy is linked to economic development and national security. Governments have often understood energy as an area of «high politics» where national interests are above collective interests. However, the evolution of the concept of energy security, the growing awareness of the need to improve access to modern energy and to avoid dangerous climate change transformed the way of confronting energy issues. Global energy governance has become the concept for analyzing international collaboration. Conceiving of global energy governance demands understanding the nature and magnitude of energy. Equally important is to know who is responsible for taking the decisions. Only then we will be able to make appropriate steps. This article focuses on both elements: why energy is a global issue and who governs it.
\end{abstract}

Keywords: energy, governance, energy security, access to energy, energy poverty, clima, climate change.

Sumario: I. INTRODUCCIÓN. II. LA ENERGÍA COMO OBJETO DE LA GOBERNANZA. 1. El sistema energético. 2. Las relaciones multidimensionales del sector energético. 3. La seguridad energética. A) Aproximación al concepto de seguridad energética. B) Implicaciones de la seguridad energética en las políticas energéticas. 4. El acceso a la energía (o pobreza energética); A) Aproximación al concepto de pobreza energética. B) Implicaciones del acceso a la energía en las políticas energéticas. 5. La energía y el clima: A) Aproximación al concepto de cambio climático. B) Implicaciones del cambio climático en las políticas energéticas. III. LAS INSTITUCIONES DE LA GOBERNANZA ENERGÉTICA GLOBAL. 1. Las cuatro tendencias institucionales para la gobernanza energética global. 2. Centralidad vs. Pluralidad. IV. REFLEXIONES FINALES. 


\section{INTRODUCCIÓN}

A comienzos del siglo XIX el consumo mundial de energía primaria estaba próximo a los quinientos millones de toneladas de petróleo equivalente. En poco más de dos siglos ese consumo se ha multiplicado por veintisiete. Las dos principales transiciones energéticas que priorizaron el uso del carbón primero y del petróleo después, junto con el desarrollo tecnológico y la generación de electricidad, posibilitaron el crecimiento económico y social a un ritmo vertiginoso. Las comodidades de los hogares, los servicios públicos, el transporte y la producción de bienes poco tienen que ver con los de hace doscientos años. Sin embargo, ese aumento en el consumo de energía y la dependencia de las fuentes fósiles también son parte de cambios en el mapa geopolítico internacional, de grandes desigualdades sociales y regionales y de riesgos medioambientales. El poder internacional de muchos Estados tiene como base las grandes reservas de petróleo que poseen y su capacidad de interrumpir el suministro. En el mundo, unos mil doscientos millones de personas (un $17 \%$ de la población mundial) no tienen acceso a la electricidad y más de dos mil setecientos millones (un 38\%) carecen de instalaciones de cocina limpias. Por otro lado, la concentración de gases de efecto invernadero, factor principal en el cambio climático, se ha triplicado, aumentando en medio grado centígrado, aproximadamente, la temperatura media terrestre. El aumento máximo soportable establecido por los científicos es de dos grados ${ }^{1}$. El aumento progresivo de la temperatura pone en tela de juicio el modelo de producción y consumo seguido por los países desarrollados y al que aspiran los países en vías de desarrollo².

La energía es un elemento clave en la seguridad de los Estados, en el desarrollo social y económico y en la sostenibilidad del planeta, lo cual genera fuertes relaciones de interdependencia entre las diferentes áreas. Sin embargo, es uno de los últimos ámbitos en incorporarse a la agenda de la gobernan-

1 Para profundizar en los datos vid. Pachauri, R. K. et al., «Climate Change 2014: Synthesis Report. Contribution of Working Groups I, II and III to the Fifth Assessment Report of the Intergovernmental Panel on Climate Change», 2014; SMIL, V., Energy Transitions: History, Requirements, Prospects, ABC-CLIO, 2010; web de la Agencia Internacional de Energía, <www.iea. org/topics/energypoverty/>.

2 SaURa Estapà, J., El cumplimiento del protocolo de Kioto sobre cambio climático, Publicacions de la Universitat de Barcelona, Barcelona, 2003, p. 9. 
za global. Tradicionalmente, los expertos en Relaciones Internacionales han entendido la gobernanza energética global como un conjunto de diferentes organizaciones encargadas de hacer frente a problemas relativamente bien definidos, estáticos y desconectados entre sí, priorizando las cuestiones geopolíticas. Los estudios se han centrado en responder la pregunta quién gobierna o quién debería gobernar y han relegado a un segundo plano las preguntas sobre el qué debe ser gobernado y el cómo.

Aunque un análisis completo sobre la gobernanza energética global requeriría abordar las tres cuestiones, la magnitud de tal tarea sobrepasa las pretensiones de este trabajo, cuyo objetivo principal es contribuir al análisis del qué y del quién. Para ello, repasaremos los elementos que conforman el sistema energético y observaremos la introducción de los diferentes aspectos energéticos en la agenda internacional que definirán los tres grandes pilares de la gobernanza energética: la seguridad energética, la pobreza energética y la lucha contra el cambio climático. Analizaremos la esencia de cada uno de ellos así como los retos que representan. La última parte de nuestro análisis, antes de las reflexiones finales, resumirá las diferentes posturas defendidas por los expertos en cuanto al quién.

\section{LA ENERGÍA COMO OBJETO DE LA GOBERNANZA}

La energía es una de las mayores preocupaciones de todos los Estados. Los países industrializados necesitan afrontar una transformación del sistema energético que requiere de financiación. Los países emergentes han de construir un sistema energético que haga de la energía un bien disponible. Las regiones más pobres o en vías de desarrollo deben luchar contra la pobreza energética ${ }^{3}$. El Secretario General de Naciones Unidas, Ban Ki-moon, la define como el hilo de oro que une el crecimiento económico, la equidad social $\mathrm{y}$ un entorno que permite que el mundo prospere ${ }^{4}$.

Los retos energéticos actuales no son problemas aislados que afectan a una sola dimensión de ámbito local, nacional, regional o global por lo que

3 World Energy Council (WEC), Highlight of the 21st World Energy Congress, Montreal 2010, 2010, p. 2.

4 KI-Moon, B., «Secretary-General to Global Development Center: 'Energy is the Golden Thread' Connecting Economic Growth, Social Equity, Environmental Sustainability. Meetings Coverage and Press Releases». 
las iniciativas y acuerdos internacionales deben considerar no sólo el objetivo concreto que los ha motivado, sino también las posibles repercusiones directas e indirectas en otras áreas y en los distintos actores que de una u otra manera se verán afectados ${ }^{5}$. Dentro del concepto de gobernanza global, el ámbito energético incluiría a todo proceso o estructura política que supere las fronteras nacionales ${ }^{6}$. Aunque el concepto de «gobernanza energética global» está todavía en construcción, se puede definir, de manera general, como la arquitectura de las instituciones y de los procesos, tanto formales e informales como públicos y privados, que contribuyen a la definición de las normas colectivas y que estructuran las relaciones energéticas mundiales ${ }^{7}$. Representa los esfuerzos colectivos internacionales emprendidos para administrar y distribuir los recursos energéticos y la prestación de servicios de energía ${ }^{8}$. Para la investigación académica supone una herramienta analítica que ayuda a dar sentido a las configuraciones socio-políticas y transformaciones actuales en el sector energético, que desafía a las insuficiencias de los enfoques nacionales en el ámbito de la energía y que reorienta los programas de resolución de problemas?

\section{El sistema energético}

En el sistema energético se pueden diferenciar tres elementos principales: las fuentes primarias, las fuentes secundarias y los servicios energéticos. Las fuentes primarias se obtienen directamente de la naturaleza. Incluyen la nuclear, los combustibles fósiles (agotables, concentrados geográficamente, almacenables y fáciles de transportar) y las renovables (inagotables y, aunque con diferencias sustanciales entre ellas, mucho menos limitadas geográficamente, intermitentes, más difíciles de almacenar y transportar y con un menor grado de densidad energética). Las fuentes secundarias se obtienen de la transformación de las fuentes primarias y representan un paso intermedio

5 Goldthau, A., «Governing Global Energy: Existing Approaches and Discourses», Current Opinion in Environmental Sustainability, vol. 3, no 4 (2011), pp. 213-214.

6 KéRÉBEL, C., «Qu'est-Ce Que La Gouvernance De L'énergie ? Les Termes Du Débat», en KéRÉBel, C. y Keppler, J. H. (eds.), La Gouvernance Mondiale De L'énergie, Institut français des relations internationales, Paris, 2009b, p. 23.

7 Ibid., p. 33.

8 Florint, A. y Sovacool, B. K., «Who Governs Energy? The Challenges Facing Global Energy Governance», Energy Policy, vol. 37, nº 12 (2009), p. 1.

9 Sovacool, B. K. y FlorinI, A., «Examining the Complications of Global Energy Governance», 7.Energy \& Nat.Resources L., vol. 30 (2012). 
que facilita el almacenamiento y transporte de la energía antes de su uso final. Los servicios energéticos representan los diferentes usos finales y varían en calidad, eficacia y facilidad con la que se pueden convertir en servicios útiles.

El siguiente gráfico nos muestra la complejidad de este sistema. Aporta una idea de la importancia de la diversidad de fuentes y del acceso a las mismas (sobre todo a la electricidad) así como del desarrollo tecnológico que se ha producido y se debe producir en el suministro de los diferentes servicios energéticos. La utilización de este esquema en diferentes divisiones territoriales muestra la diversidad de matrices energéticas y la disparidad entre ellas, advirtiendo de la dificultad de aunar todos los intereses en un solo sistema.

Gráfico 1: Elementos básicos del sistema energético

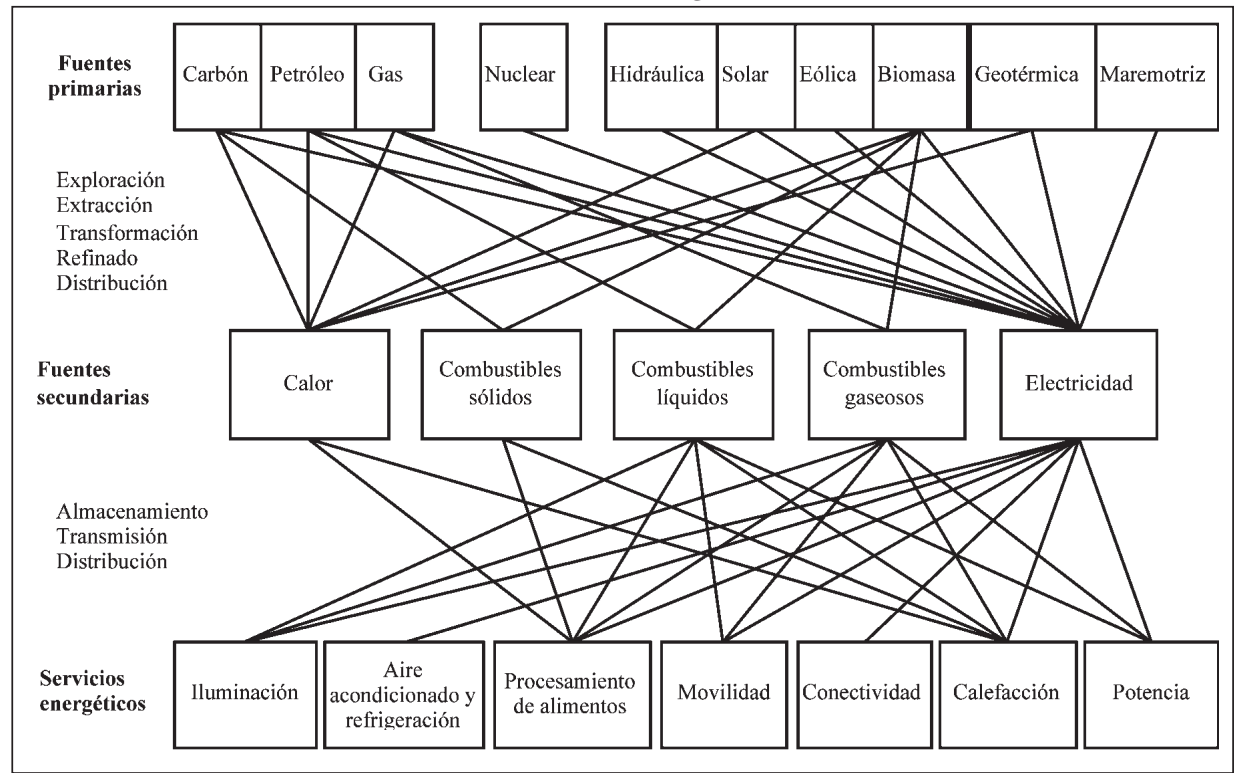

Fuente: Elaboración propia basada en el gráfico de R. Bailis ${ }^{10}$

A lo largo de la historia, las sociedades han generado distintos modelos energéticos condicionados por sus fuentes de energía y su aprovechamiento. La innovación técnica, la aparición de nuevos mercados de energía y un cons-

10 Bailis, R., «Energy and Poverty: The Perspective of Poor Countries», en Galarraga, I.; GonZÁlez-Eguino, M. y MARKANDYA, A. (eds.), Handbook of Sustainable Energy, Edward Elgar Publishing, 2011, p. 507. 
tante aumento de la demanda de servicios energéticos más eficientes, económicos y flexibles impulsan estos cambios ${ }^{11}$. La adopción y la difusión de nuevas fuentes de energía o de nuevos convertidores tienen consecuencias económicas y sociales. El desarrollo de herramientas y el control del fuego hicieron posible dejar la vida nómada de los recolectores y cazadores y evolucionar hacia sociedades sedentarias agrícolas y ganaderas, lo que promovió un aumento en la densidad de población, la especialización laboral, la estratificación social, la urbanización y el comercio. Pero todos estos cambios necesitaron de miles de años para producirse. La industrialización basada en los combustibles fósiles, la electricidad y los motores de combustión interna rompieron el ritmo de evolución acelerándolo hasta el punto en que apenas se necesitaron unas generaciones para que el modelo se transformase ${ }^{12}$.

La transición de un modelo energético a otro no sucede de forma global ni es uniforme allí donde se produce, sin embargo, una de las características de las sociedades modernas es que son sociedades con un alto consumo energético. La gobernanza energética global debe responder a la necesidad de cambiar el modelo energético vigente hacia un modelo más sostenible, entendiendo por ello un modelo de desarrollo socio-económico que haga un uso racional de los recursos naturales para no comprometer su existencia ni hipotecar la satisfacción de las necesidades de futuras generaciones ${ }^{13}$. Por otra parte, el sector energético está presente en todos niveles de análisis (sectorial, nacional y global). Lo que ocurra en un nivel tendrá su efecto en los demás. Por todo ello se requiere un compromiso por parte de todos los actores en la elaboración de políticas energéticas globales.

\section{Las relaciones multidimensionales del sector energético}

La complejidad de la gobernanza energética global tiene su base en su composición plural. El sector energético se caracteriza por mantener relaciones de interdependencia multidimensionales y multinivel, por lo que es un error elaborar políticas individuales que no tengan en cuenta estas relaciones pues acabarían siendo políticas insuficientes e ineficaces. Su incorporación a

\footnotetext{
SMIL, V., Energy Transitions..., op. cit., pp. 17-18.

12 SMIL, V., Energy in World History, Westview Press, Boulder, CO, 1994.

13 GaTTO, M., «Sustainability: Is it a Well Defined Concept?», Ecological Applications, vol. 5, n ${ }^{\circ} 4$ (nov., 1995); DARNACULleTA I GARDELla, M., Recursos naturales y dominio público: el nuevo régimen de demanio natural, Cedecs, Barcelona, 2000, pp. 52-53.
} 
los debates internacionales y a los estudios de las Relaciones Internacionales como objeto único de estudio y de gestión se ha producido durante las últimas décadas. Pero esto no significa que haya estado totalmente ausente. A lo largo del tiempo, diferentes aspectos vinculados al sector energético han ido ganando en relevancia e interés. Según sea el criterio seguido, los expertos proponen diversas formas de clasificar y relacionar las dimensiones que participan en el ámbito energético.

Tabla 1. Clasificación según Cherp, Jewell y Goldthau

\begin{tabular}{|c|c|c|c|}
\hline Áreas & $\begin{array}{l}\text { Contexto } \\
\text { histórico }\end{array}$ & Actores y organizaciones & $\begin{array}{l}\text { Principales } \\
\text { objetivos }\end{array}$ \\
\hline $\begin{array}{l}\text { Seguridad } \\
\text { energética }\end{array}$ & $\begin{array}{l}\text { Las crisis del } \\
\text { petróleo en los } \\
\text { años setenta. }\end{array}$ & $\begin{array}{l}\text { - Alianzas: OPEP, AIE y G8. } \\
\text { - Plataformas: Foro Internacional } \\
\text { de la Energía (FIE), OLADE y } \\
\text { Organización de Cooperación de } \\
\text { Shangai (SCO). } \\
\text { - Acuerdos entre Estados. }\end{array}$ & $\begin{array}{l}\text { Suministro de energía } \\
\text { global de manera } \\
\text { estable y segura. }\end{array}$ \\
\hline $\begin{array}{l}\text { Acceso a la } \\
\text { energía }\end{array}$ & $\begin{array}{l}\text { Enmarcado } \\
\text { en la agenda } \\
\text { internacional } \\
\text { del desarrollo de } \\
\text { los ochenta. }\end{array}$ & $\begin{array}{l}\text { - Organizaciones Internacionales } \\
\text { de Desarrollo, Bancos de } \\
\text { Desarrollo Internacionales y } \\
\text { Regionales, ONGs y Asociaciones } \\
\text { Multilaterales de Ayuda. }\end{array}$ & $\begin{array}{l}\text { Acceso a formas } \\
\text { modernas de energía. }\end{array}$ \\
\hline $\begin{array}{l}\text { Cambio } \\
\text { climático }\end{array}$ & $\begin{array}{l}\text { La } \\
\text { sostenibilidad } \\
\text { medioambiental } \\
(1990-2000) .\end{array}$ & $\begin{array}{l}\text { - Estado-Naciones, Organizaciones } \\
\text { Intergubernamentales, ONGs } \\
\text { y Asociaciones Transnacionales } \\
\text { (IRENA, REEP). }\end{array}$ & $\begin{array}{l}\text { Reducción de } \\
\text { gases de efecto } \\
\text { invernadero; bosques; } \\
\text { uso adecuado de la } \\
\text { tierra y adaptación al } \\
\text { cambio climático. }\end{array}$ \\
\hline
\end{tabular}

Fuente: Elaboración propia

Observando el contexto histórico y las agendas políticas, A. Cherp, J. Jewell y A. Goldthau establecen un sistema tridimensional compuesto por la seguridad energética, el acceso a la energía y el cambio climático. Estos tres ejes serán considerados como los tres pilares de la gobernanza energética. Otros autores también incluyen los derechos humanos ${ }^{14}$. La preocupación por

14 Florin, A. y Sovacool, B. K., «Bridging the Gaps in Global Energy Governance», Global Governance: A Review of Multilateralism and International Organizations, vol. 17, $\mathrm{n}^{\circ} 1$ (2011), p. 66. 
Tabla 2. Clasificación según Florini y Sovacool

\begin{tabular}{|c|c|}
\hline Áreas & Desafíos \\
\hline $\begin{array}{l}\text { Geopolítica y } \\
\text { Seguridad }\end{array}$ & $\begin{array}{l}\text { - Conflictos entre Estados por recursos energéticos. } \\
\text { - Vulnerabilidad de las infraestructuras energéticas ante el terrorismo y } \\
\text { perturbaciones por accidentes industriales y cambio climático. } \\
\text { - Expansión del uso civil de la energía nuclear y necesidad de reforzar el } \\
\text { régimen internacional de no proliferación (TNP). } \\
\text { - Debilidad de la AIEA para llevar a cabo sus mandatos. } \\
\text { - Opacidad de las políticas energéticas de algunos países. } \\
\text { - Concentración de las reservas internacionales conocidas de petróleo en } \\
\text { Estados impredecibles. }\end{array}$ \\
\hline $\begin{array}{l}\text { Economía } \\
\text { política de la } \\
\text { energía }\end{array}$ & $\begin{array}{l}\text { - Influencia de las regulaciones anacrónicas, los obstáculos comerciales y los } \\
\text { derechos de propiedad intelectual en la inversión. } \\
\text { - No difusión de tecnología entre países por barreras comerciales y costes de } \\
\text { patentes. } \\
\text { - Subvenciones a los combustibles fósiles y a la energía nuclear. } \\
\text { - Impacto negativo de algunas normas comerciales de la OMC sobre el } \\
\text { fomento de buenas políticas energéticas. }\end{array}$ \\
\hline $\begin{array}{l}\text { Externalidades } \\
\text { transfronterizas }\end{array}$ & $\begin{array}{l}\text { - Múltiples amenazas causadas por el cambio climático. } \\
\text { - Riesgos y contaminación del uso de sistemas energéticos. } \\
\text { - Coste de las externalidades negativas derivadas de la dependencia de } \\
\text { combustibles fósiles y de la reducción de emisiones de } \mathrm{CO}_{2} \text {. }\end{array}$ \\
\hline $\begin{array}{l}\text { Desarrollo y } \\
\text { Energía }\end{array}$ & $\begin{array}{l}\text { - Pobreza energética y acceso limitado a servicios energéticos modernos. } \\
\text { - Necesidad de más inversiones externas y de ayuda al desarrollo para lograr una } \\
\text { transición hacia un sistema energético sostenible. } \\
\text { - Dependencia de los países en desarrollo de empresas extranjeras para la } \\
\text { extracción y los derechos humanos en la industria de extracción. } \\
\text { - Financiación mayoritaria del Banco Mundial a plantas de combustibles fósiles. }\end{array}$ \\
\hline $\begin{array}{l}\text { Asuntos } \\
\text { emergentes en } \\
\text { la gobernanza } \\
\text { global y en } \\
\text { las políticas } \\
\text { energéticas }\end{array}$ & $\begin{array}{l}\text { Gestión del agua y de la tierra por su influencia en: } \\
\text { - Presas hidroeléctricas } \\
\text { - Transporte de combustibles } \\
\text { - Plantas termoeléctricas } \\
\text { - Instalaciones de petróleo y gas, refinerías, destilerías de etanol e industria } \\
\text { - Mecanismos para solucionar los conflictos transnacionales sobre agua } \\
\text { - Necesidad de redes internacionales de expertos }\end{array}$ \\
\hline
\end{tabular}

Fuente: A. Florini and B. K. Sovacool ${ }^{15}$.

la seguridad en el suministro de energía -o seguridad energética- alcanza su máxima expresión con las crisis del petróleo de la década de los setenta. Una década después y en el marco de la agenda de desarrollo internacional será el

15 Ibid., p. 58. 
acceso a la energía el tema central del debate. Por último, el cambio climático, estrechamente relacionado con la sostenibilidad del medio ambiente, se convertirá en la preocupación dominante en la década de $1990^{16}$.

Los autores A. Florini y B. K. Sovacool ${ }^{17}$ han tomado como referencia para su análisis las posibles relaciones entre la prestación de servicios de energía y el despliegue de las tecnologías con las dimensiones geopolítica, ambiental y económica. Sugieren la existencia de cinco áreas: 1) la geopolítica y la seguridad; 2) las externalidades transfronterizas; 3) la economía política de la energía; 4) el desarrollo y la energía; y 5) los asuntos emergentes en la gobernanza global y en las políticas energéticas.

Ambas aproximaciones son complementarias. En ambos casos, cada nivel de clasificación es plural, por lo que no sorprende observar múltiples relaciones compartidas entre todos ellos. Tomando como base los tres pilares de la gobernanza energética, vemos, por ejemplo, que tanto la seguridad, como la pobreza energética y el cambio climático están relacionados con la economía y el mercado, el desarrollo (social, económico y tecnológico) y la sostenibilidad medioambiental, aunque la importancia que se le conceda a cada área o el número de elementos que compartan sea diferente en cada caso. Otros ámbitos con los que también se establecen relaciones son los diferentes usos de la energía nuclear y las prácticas de buen gobierno. De ello se deduce la existencia de un cierto solapamiento en la gestión de cada uno de los tres grandes pilares, por lo que es necesario examinar más a fondo cada uno de ellos.

\section{La seguridad energética}

La seguridad energética es de vital importancia para todas las partes interesadas, incluyendo gobiernos, empresas y consumidores. Sin embargo, no existe un consenso sobre la definición del concepto. Según L. Chester «el concepto de seguridad energética es inherentemente 'resbaladizo' por su naturaleza polisémica, capaz de albergar múltiples dimensiones y de asumir diferentes especificidades en función del país (o continente), período de tiempo o fuente de energía a la que se aplica» ${ }^{18}$. Depende en un alto grado de las

16 Cherp, A.; Jewell, J. y Goldthau, A., «Governing Global Energy: Systems, Transitions, Complexity», Global Policy, vol. 2, n 1 (2011), pp. 81-83.

17 Florini, A. y Sovacool, B. K., «Bridging the Gaps...», loc. cit., p. 57.

18 CHester, L., «Conceptualising energy security and making explicit its polysemic nature», Energy Policy, vol. 38, nº 2 (February 2010), pp. 887-895. 
circunstancias nacionales pero también del contexto internacional. Influyen la solidez del modelo energético y la geopolítica pero también el nivel de desarrollo económico y tecnológico y las percepciones sobre riesgos endógenos y exógenos al mismo. Algunos autores se centran en aspectos como la disponibilidad y los precios mientras que otros prefieren enfocarse en cuestiones como el impacto económico y social o la sostenibilidad. La evolución que ha experimentado el concepto de seguridad energética a lo largo del tiempo, ampliando su definición y los elementos que hay que considerar al tratar de establecer que parte del qué representa, le convierte en una cuestión clave, pero a la vez complicada de gestionar.

a) Aproximación al concepto de seguridad energética

El origen del concepto de «seguridad energética» está ligado a la decisión del Lord del Almirantazgo Winston Churchill de sustituir el carbón por petróleo como fuente motora de los buques de la marina británica. No fue una decisión arbitraria. El petróleo ofrecía unas ventajas tácticas considerables sobre el carbón -era más eficiente y aumentaba la velocidad de los navíos- al tiempo que era más ligero, limpio y fácil de almacenar y de $\operatorname{transportar}^{19}$. Sin embargo, también planteaba un nuevo problema: la dependencia de un recurso que no se hallaba en subsuelo británico, sino en una región inestable a seis mil millas de distancia: el actual Irán. Ante las críticas a su decisión por este motivo, Churchill ofreció una de las claves que a día de hoy se consideran esenciales para garantizar la seguridad. Churchill apeló a la diversidad de suministradores ${ }^{20}$. Pero el año clave en materia de seguridad energética fue 1973. Ese año la seguridad energética adquirió una dimensión internacional. El incesante aumento del consumo de petróleo cambió el equilibro geopolítico internacional ya que algunos países como Estados Unidos, aun siendo productores, no podían satisfacer su demanda, lo que convirtió a los países del Golfo en los productores (y suministradores) incuestionables. En octubre de 1973 estos países, agrupados en la Organización de Países Árabes Exportadores de Petróleo (OPAEP), demostraron la eficacia de utilizar el

19 Yergin, D., The Quest: Energy, Security, and the Remaking of the Modern World, Penguin, 2011, pp. 266-267; SingH, B. K., India's Energy Security: The Changing Dynamics, Pentagon Press, 2010, p. 15.

20 Yergin, D., The Quest..., op. cit., p. 267. 
petróleo como instrumento de presión internacional. Las subidas de precio y el embargo impuesto a algunos países como consecuencia de la III Guerra Árabe-Israelí tuvieron un gran impacto en la economía mundial. Un año más tarde, los países consumidores se aliaban para formar la Agencia Internacional de la Energía (AIE).

Desde entonces, y durante las siguientes dos décadas, el debate sobre seguridad energética estuvo dominado por el aspecto geopolítico, por garantizar la seguridad de acceso a la energía, entendiendo seguridad en el concepto más clásico y realista del término. La seguridad nacional, según apunta $\mathrm{B}$. K. Singh, incluye la seguridad militar, la seguridad política, la seguridad social, la seguridad económica, la seguridad alimentaria, la seguridad del medio ambiente y la seguridad energética ${ }^{21}$. Como elemento del tradicional concepto de seguridad, los Estados compiten por el acceso a los recursos energéticos claves para la prosperidad y el poder estatal siguiendo las reglas de los juegos de suma cero. La seguridad de suministro de petróleo estuvo en el núcleo de las políticas energéticas. Algunos grandes consumidores centraron su atención en el poder de extorsión política de los productores y la vulnerabilidad de los consumidores, por lo que defendieron políticas cuyo objetivo principal era la independencia energética. Otros se concentraron en la fiabilidad del suministro. Pero todos (consumidores y productores) comparten un objetivo común, puramente económico: evitar la volatilidad de los precios y proteger la economía contra las interrupciones de suministro ${ }^{22}$.

Esta aproximación sigue siendo válida aunque limitada en la actualidad. Con el paso del tiempo, nuevos elementos de preocupación se han ido introduciendo en el ámbito de la seguridad energética que han provocado no solo una expansión y difusión de la definición del término, sino también un incremento en el interés por parte de los expertos. Las vulnerabilidades de los sistemas técnicos complejos, los límites globales y el papel de los mercados y de las inversiones abrieron las puertas de las ciencias naturales, la ingeniería y la economía a los discursos sobre la seguridad energética. La seguridad energética ya no se basa únicamente en los posibles conflictos entre Estados por el

21 SINGH, B. K., op. cit., p. 2.

22 WinZER, C., «Conceptualizing Energy Security», Energy Policy, vol. 46, 2012, pp. 36-48. Para un desarrollo sobre las estrategias energéticas de países productores y consumidores véase el artículo de Palazuelos, E., «Alternativas estratégicas en torno al petróleo y al gas natural, en Petróleo y gas en la geoestrategia mundial, Akal, Madrid, 2009», Relaciones internacionales: Revista académica cuatrimestral de publicación electrónica, nº 11 (2009), pp. 5-16. 
dominio de los recursos, sino que considera otros aspectos como los apagones y la escasez crónica -o fiabilidad- del suministro eléctrico ${ }^{23}$, la disponibilidad de combustibles alternativos al petróleo como el gas, los asuntos económicos y los precios y, en ocasiones, asuntos sociales y medioambientales ${ }^{24}$. Las preocupaciones de la seguridad energética y medioambiental se han fusionado y las amenazas se han diversificado ${ }^{25}$.

B. K. Sovacool ${ }^{26}$, agrupa los retos en tres grandes niveles: el nivel macro (los riesgos globales, transnacionales y supranacionales), el nivel micro (los riesgos locales y domésticos) y el nivel medio (los riesgos transversales horizontales y verticales, que afectarían a los sistemas energéticos y a tecnología específica). Dentro del primer nivel, como riesgos globales, el autor identifica tres áreas: la geopolítica y la guerra; las barreras a la inversión; y las externalidades transfronterizas (cuestiones medioambientales). En el segundo nivel, los riesgos toman la forma de desigualdad en el acceso a la energía, de pobreza energética y de contaminación. En el último de los niveles engloba los retos que afectan a los combustibles fósiles, la energía nuclear, las presas hidroeléctricas y la tecnología de las renovables a pequeña escala.

Por su parte, B. Johansson ${ }^{27}$ explica los diferentes retos basándose en las dos dimensiones de la seguridad: la objetiva y la subjetiva. En la dimensión objetiva, el sistema energético es el objeto amenazado que tiene que ser protegido. Se refiere a la seguridad del suministro y a la seguridad de la demanda. Los riesgos provienen, por ejemplo, de una mala infraestructura, de la escasez de recursos, de la inadecuación del mercado, de los precios o de la falta de inversión. En la dimensión subjetiva, el sistema energético es el origen de las amenazas. En este caso, los riesgos se originan por el valor económico y político de la energía, por fallos en la tecnología utilizada (seguridad física) y por no ser respetuoso con el medio ambiente.

23 Florini, A., «Global Governance and Energy», en C. Pascual y J. Elkind (eds.), Energy Security: Economics, Politics, Strategies and Implications, Brookings Institution Press, 2010: 151-152; YerGIN, D., «Ensuring Energy Security», Foreign Affairs (2006), pp. 69-82.

24 Cherp, A. y Jewell, J., «The Three Perspectives on Energy Security: Intellectual History, Disciplinary Roots and the Potential for Integration», Current Opinion in Environmental Sustainability, vol. 3, nº 4 (2011), pp. 208-209.

25 KuiK, O. J.; Lima, M. B. y GuPTA, J., «Energy Security in a Developing World», Wiley Interdisciplinary Reviews: Climate Change, vol. 2, no 4 (2011), p. 628.

26 Sovacool, B. K., The Routledge Handbook of Energy Security, Routledge, 2011, pp. 11-31.

27 Johansson, B., «A Broadened Typology on Energy and Security», Energy, vol. 53, 2013. 
Todas estas clasificaciones ponen de manifiesto que la seguridad energética puede ser abordada desde diferentes perspectivas. Trabajos de autores como B. K. Sovacool, B. W. Ang, W. L. Choong y T. S. Ng o C. Winzer ${ }^{28}$ así lo demuestran. B.W. Ang, W.L. Choong y T.S. Ng, por ejemplo, analizan 104 estudios (arts. de revistas científicas e informes de agencias nacionales, organizaciones internacionales y empresas/asociaciones profesionales) sobre seguridad energética realizados por diferentes organismos entre 2001 y 2014. De ellos extraen siete dimensiones recurrentes: disponibilidad, infraestructura, precios, efectos sociales, medio ambiente, gobernanza y eficiencia. Un análisis cuantitativo de los documentos que incluyen cada dimensión en la definición de seguridad energética muestra la importancia de cada una ellas. Como no es de extrañar, las dimensiones que hacen referencia a la interpretación clásica de seguridad-disponibilidad, infraestructura y precios- son las que más aparecen (en 82, 60 y 59 textos respectivamente). A continuación aparece la cuestión medioambiental (31) seguida por los efectos sociales (28), la gobernanza (21) y la eficiencia (18). La división de los catorce años en tres periodos (20012005, 2006-2009, 2010-2014) aporta dos matices importantes a ese análisis: la relación entre las diferentes dimensiones en los diferentes momentos y el aumento del interés por la seguridad energética, reflejado en el número de estudios de cada periodo.

Gráfico 2. Dimensiones de la seguridad energética en las definiciones según el momento

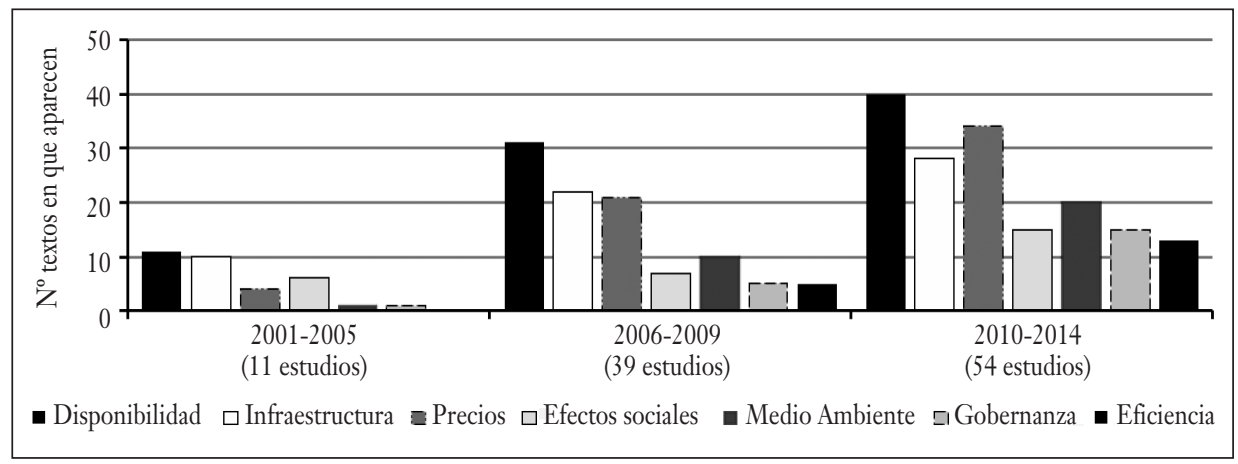

Fuente: Elaboración propia basada en el gráfico de B.W. Ang, W.L. Choong y T.S. Ng.

28 Vid. Sovacool, B. K., op. cit.; Ang, B. W.; Choong, W. L. y NG, T. S., «Energy Security: Definitions, Dimensions and Indexes», Renewable and Sustainable Energy Reviews, vol. 42, n 2 (2015); WINZER, C., op. cit. 
Otros autores utilizarán diferentes criterios para realizar sus estudios, ofreciendo distintas aproximaciones al concepto de seguridad energética. Por ejemplo C. Winzer analizará más de una treintena de definiciones basándose en atributos como las fuentes de riesgo y el alcance de los mismos. B. K. Sovacool, por su parte, propone más de 200 indicadores para el análisis de un concepto que considera politizado y multifacético ${ }^{29}$.

b) Implicaciones de la seguridad energética en las políticas energéticas

Otro elemento que dificulta una aproximación universal a la seguridad energética se deriva de las diferentes interpretaciones que, dependiendo de los intereses del sujeto, se dan sobre cada uno de los elementos que participan en ella. Quizá el ejemplo más claro de esta situación sea el precio. Para los países desarrollados, la definición habitual de seguridad energética es simplemente la disponibilidad de un suministro suficiente a precios asequibles. En cambio, los países exportadores de petróleo están centrados en mantener la «seguridad de la demanda» de sus exportaciones porque suponen la mayor parte de los ingresos estatales. En cuanto a los países en desarrollo, su preocupación se centra en las consecuencias de los precios cambiantes de la energía sobre su balanza de pagos ${ }^{30}$. Asimismo, un precio asequible será interpretado de forma diferente por cada actor (público, industria y sociedad civil) que participe en cada grupo (consumidores, productores y en vías de desarrollo).

A pesar de ello, la mayoría de los autores coinciden en señalar como elementos básicos en la definición moderna de seguridad energética los conocidos como «las 4 Aes» (por su terminología inglesa): disponibilidad (availability), accesibilidad (accessibility), asequibilidad (affordability) y aceptación (acceptability), introducidas por el Centro de Investigación en Energía de Asia Pacífico (APERC) en 2007. Algunos autores prefieren el término sostenibilidad al de aceptación. De las cuatro, las dos primeras (disponibilidad y accesibilidad) ya estaban presentes en la concepción clásica. Las dos últimas no se relacionarán con la energía hasta el informe del APERC ${ }^{31}$. Últimamente también está ganando peso el término de eficiencia.

Sovacool, B. K., op. cit.

30 YeRGIN, D., loc. cit., pp. 69-82.

31 Cherp, A. y Jewell, J., «The Concept of Energy Security: Beyond the Four As», Energy Policy, vol. $75, \mathrm{n}^{\circ} 12,2014$. Es interesante destacar cómo estos cuatro elementos coinciden con las áreas identificadas como pilares de la gobernanza energética y los retos de la seguridad energética esto es, fiabilidad (seguridad), asequibilidad (acceso) y sostenibilidad (cambio climático). 
La disponibilidad y la fiabilidad significan un acceso regular e ininterrumpido (con independencia de cuáles sean las causas) a la cantidad y forma de energía que se necesite. Hacen referencia a la independencia y a la diversificación. La independencia energética debe ser entendida como una independencia relativa y no absoluta, es decir, no implica que toda la demanda sea cubierta con producción nacional ${ }^{32}$. Por su parte, la diversificación engloba tres aspectos: la diversificación de fuentes (una matriz energética variada), la diversificación de suministradores (diferentes productores y/o empresas) y la diversificación espacial o geográfica de las instalaciones (refinerías, cadena de procesamiento, transporte y distribución final) ${ }^{33}$. Esta diversificación implica la existencia de un mercado energético bien informado, con recursos suficientes en el que los compradores y vendedores están de acuerdo en las condiciones. También implica inversión y desarrollo tecnológico así como la elaboración de marcos jurídicos y normativos.

Los mercados energéticos y la configuración del comercio internacional de la energía se han transformado profundamente en los últimos años debido a un aumento significativo de los actores que intervienen, lo que está provocando una evolución en las relaciones de poder. Las reglas del juego energético han cambiado ${ }^{34}$. La gobernanza trata de determinar quiénes son los jugadores en el juego de la energía, cuáles son sus intereses, cómo intentan maximizar sus expectativas y cómo las instituciones de los mercados energéticos les influyen. También observa el papel de los Estados como guardianes de que se cumplan las reglas del juego ${ }^{35}$.

La asequibilidad hace referencia a un acceso equitativo a los servicios energéticos a unos precios bajos, estables y económicamente sostenibles que promocionen el crecimiento económico ${ }^{36}$. Del lado de la oferta, el precio debe responder a las exigencias de beneficio y de realización de las inversiones imprescindibles para garantizar el futuro de la misma. Un precio excesivamente alto puede ser perjudicial desde el momento en que incida negativamente en las economías de los países consumidores y repercuta en la futura salida de la producción. Del lado de la demanda, el precio no debe poner en riesgo su

\footnotetext{
Shaffer, B., Energy Politics, University of Pennsylvania Press, 2011, p. 91.

Sovacool, B. K., op. cit., p. 9.

34 Kérébel, C., «Qu'est-Ce Que La Gouvernance De L'énergie...», loc. cit., p. 17.

35 Goldthau, A. y Witte, J. M., «From Energy Security to Global Energy Governance», fournal of Energy Security (2010).

36 Sovacool, B. K., op. cit., p. 9.
} 
competitividad, en la medida en que afecte a sus costes, ni dificultar su presencia en los mercados internacionales. Ahora bien, un precio excesivamente bajo tampoco es de su interés, ya que puede desalentar las inversiones que hagan posible su abastecimiento futuro. Es interesante llamar la atención sobre el hecho de que tanto países productores como consumidores pueden coincidir en la conveniencia de precios estables que satisfagan sus respectivas preocupaciones, pero la complejidad de las fuerzas que se encuentran detrás de la formación de los mismos contribuye a obstaculizar enormemente esa posibilidad.

La aceptación o sostenibilidad, está directamente relacionada con las cuestiones medioambientales. Una de las razones del aumento de la contaminación y la emisión de Gases de Efecto Invernadero (GEI), principalmente $\mathrm{CO}_{2}$, estriba en que los precios de la energía no tienen en cuenta los costos asociados a la destrucción medioambiental y el cambio climático. Conviene señalar, no obstante, que parte de la innovación tecnológica está orientada a la obtención de combustibles fósiles menos contaminantes, la mayor eficiencia de las plantas de generación eléctrica o la captura y posterior almacenamiento del $\mathrm{CO}_{2}$ producido.

Junto a las «4 Aes», un elemento que cada vez está ganando más peso es el de eficiencia. Podemos definir eficiencia energética como la minimización de los recursos energéticos empleados para la realización de una tarea determinada sin afectar negativamente al resultado final. Es decir, busca optimizar el proceso mientras se disminuye el consumo. La eficiencia energética se puede conseguir mediante el desarrollo tecnológico, los cambios en los hábitos de consumo y la sustitución de insumos o combustibles por otros energéticamente más económicos.

De tomar en cuenta únicamente las cuestiones de disponibilidad, fiabilidad y asequibilidad, se estaría priorizando la utilización del petróleo, gas y carbón. Pero este enfoque resulta cada vez más inviable por sus consecuencias medioambientales. La inclusión de una dimensión de sostenibilidad permitirá la adopción de políticas con una mayor visión de futuro. La eficiencia energética se puede aplicar a todas las fuentes y tiene efectos positivos sobre todos los ámbitos por lo que también es imprescindible su inclusión.

\section{El acceso a la energía (o pobreza energética)}

El acceso a la energía está directamente relacionado con el desarrollo. Sin embargo, más de mil trescientos millones de personas en el mundo (aproximadamente el $18 \%$ de la población total) no tienen acceso a la electricidad. 
De ellas, casi el 97\% residen en los países menos desarrollados de Asia y en el África subsahariana. El 84\% se encuentra en zonas rurales. Además, dos mil seiscientos millones de personas (un 38\% de la población mundial) carecen de instalaciones de cocina limpias. En este caso Asia, y especialmente India, son los más afectados ${ }^{37}$.

A pesar de estas cifras, el acceso a la energía, a diferencia de lo que ocurre con los otros dos grandes pilares de la gobernanza energética, no ha formado parte, al menos de manera relevante, en los procesos políticos internacionales y cuando forma parte de la agenda, suele estar unida a otros objetivos como la calidad de vida, las oportunidades o el desarrollo sostenible. Incluso en las iniciativas de Naciones Unidas centradas en la pobreza y el desarrollo, el acceso a la energía está en una posición delicada al situarse en el centro de la tensión entre desarrollo sostenible y desarrollo económico, especialmente en los países en vías de desarrollo. Hay quien interpreta la ausencia de un apartado específico dentro de los Objetivos del Milenio (ODM) o un indicador que mida el progreso de estos objetivos relacionado con la pobreza energética como una clara manifestación de estas tensiones ${ }^{38}$. Cabe destacar, no obstante, que esta ausencia parece haber sido corregida en la agenda de desarrollo para después de 2015.

a) Aproximación al concepto de pobreza energética

Como viene siendo lo característico en este campo de estudio, tampoco existe una única definición del concepto «acceso a la energía»o «pobreza energética». Algunos estudios identifican pobreza energética con la cantidad de energía y tipo de combustible consumidos. En ocasiones, se ha utilizado el concepto de «escalera energética» para ilustrar la pobreza energética. La idea en la que se basa es sencilla: cada peldaño de la escalera representa un tipo de combustible, con los más básicos en los primeros peldaños y los más avanzados, en términos de eficiencia, en los peldaños superiores. A medida que mejora la situación, se avanza en la escalera. Otros autores prefieren fijarse en los servicios energéticos consumidos, es decir, calefacción, luz y transporte público o privado. Según el PNUD (Programa de las Naciones Unidas para el Desarrollo) el

37 International Energy Agency (IEA), World Energy Outlook 2014, IEA, 2014, p. 73.

38 Dubash, N. K. y Florini, A., «Mapping Global Energy Governance», Global Policy, vol. 2 (2011), p. 9. 
sistema energético se compone de dos partes: una es el sector que suministra la energía y la otra las tecnologías de uso final de la energía. El objetivo del sistema energético es ofrecer a los consumidores los beneficios de la energía. Esos beneficios -la iluminación, la generación de calor o frío, la cocción de alimentos y el transporte para el sector individual (hogares) y todos aquellos que requieren las actividades comerciales e industriales- son lo que conocemos o denominamos como «servicios energéticos». Con esto en mente, el PNUD define pobreza energética en referencia a la carencia de combustibles modernos para cocinar y de iluminación eléctrica necesaria para realizar actividades tras haber anoche$\operatorname{cido}^{39}$. Un tercer grupo de autores utilizan un enfoque más amplio. A. Cherp ${ }^{40}$ se refiere al acceso a servicios energéticos limpios, asequibles y estables, suministrados de forma fiable y con una calidad constante. Por su parte, A. K. N. Reddy ${ }^{41}$ la define como la falta de «alternativas suficientes» para acceder a unos servicios energéticos adecuados, económicos, fiables, seguros y ambientalmente sostenibles que ayuden al desarrollo económico y humano. Se observa pues, que, al igual que ocurría con la seguridad energética, la fiabilidad del suministro, la asequibilidad y la sostenibilidad son también elementos claves de este pilar de la gobernanza energética.

A menudo existe una relación bidireccional y viciosa entre la falta de acceso a los servicios energéticos modernos y asequibles y la pobreza (en su sentido más genérico). La población con menos recursos económicos, a pesar de emplear una considerable parte de ellos en la obtención de servicios energéticos, tan sólo tienen acceso a servicios pobres e inseguros que en muchas ocasiones, como sucede al utilizar la biomasa tradicional (madera, carbón y estiércol no procesados) en el uso doméstico diario, pone en peligro la salud. La transición de una economía basada en la agricultura hacia una economía industrial moderna y orientada hacia los servicios requiere de servicios energéticos adecuados y asequibles ${ }^{42}$.

39 GaYE, A., «Access to Energy and Human Development», Human Development Report, vol. 2008, 2007, p. 4.

40 Cherp, A. et al., «Energy and Security», Global Energy Assessment (GEA) Toward a Sustainable Future, Cambridge University Press, 2012, p. 157

41 REDDY, A. K. N., «Energy and Social Issues», Energy and the Challenge of Sustainability. World Energy Assessment, UNPD, New York, 2000, <www.undp.org/content/dam/aplaws/publication/ en/publications/environment-energy/www-ee-library/sustainable-energy/world-energy-assessment-energy-and-the-challenge-of-sustainability/World\%20Energy\%20Assessment-2000. pdf $>$, p. 44.

42 Florini, A., loc. cit., pp. 155-156; Cherp, A. et al., loc. cit., p. 153 
Los servicios de energía seguros y eficientes, y sobre todo el caso de la electricidad, es esencial para logar el desarrollo económico, lo que permite el comercio, la fabricación, la distribución y el transporte de materias primas y productos manufacturados. Además, la reducción de la dependencia de los combustibles fósiles costosos para la generación eléctrica, la industria y el transporte no sólo contribuye a la lucha contra el cambio climático sino que también supone un ahorro (o, al menos, la disponibilidad de ciertos recursos económicos) y reduce las incertidumbres producidas por la volatilidad de los precios o de la disponibilidad de suministro. Sin olvidar que el trabajo necesario para la adecuación de los sistemas de energía sirve como un estímulo para la creación de empleo y el desarrollo económico ${ }^{43}$.

El acceso a formas modernas de energía es esencial para superar la pobreza, para el crecimiento económico y, en general, para promover el desarrollo humano sostenible. Es habitual encontrar referencias que relacionan la pobreza energética con la productividad, la salud, la educación y el género y la degradación del medio ambiente.

b) Implicaciones del acceso a la energía en las políticas energéticas

Cualquier solución requiere primero entender el problema. Y esto depende, en gran medida, de la adecuación de los indicadores de medición y control. S. Pachauri y D. Spreng ${ }^{44}$ y S. Pachauri y A. Cherp ${ }^{45}$ dan cuenta de tres tipos de indicadores complementarios utilizados en la medición de la pobreza energética: los indicadores tecnológicos, los físicos y los económicos, ya que cada uno de ellos carece de la información que aportan los demás. Los tecnológicos ofrecen datos sobre el acceso a servicios energéticos modernos, entendidos estos como acceso a la electricidad y a fuentes alternativas a la biomasa tradicional para cocinar y para la calefacción. Los físicos y los económicos analizan los niveles de adecuación en base a unos niveles mínimos establecidos. Así, los datos físicos analizan el consumo de energía en relación al nivel mínimo de consumo energético asociado a las necesidades básicas. Su principal problema radica en la disparidad en cuanto a qué se considera una

43 United Nations Department Of Economic And Social Affairs (UNDESA), Synthesis of Energy Related Issues Highlighted in National Reports of Rio+20, 2012.

44 Pachuri, S. y Spreng, D., «Measuring and Monitoring Energy Poverty», Energy Policy, vol. 39, $\mathrm{n}^{\mathrm{o}} 12, \mathrm{n}^{\mathrm{o}} 12(2011)$.

45 Pachuri, S.; Spreng, D. and Cherp, A., «Energy Security and Energy Access: Distinct and Interconnected Challenges», Current Opinion in Environmental Sustainability, vol. 3, nº 4 (2011). 
necesidad básica. También está la duda de si hay que incorporar en esa medición la energía utilizada para usos productivos o no. Los datos económicos, por su parte, analizan la situación según el porcentaje máximo de renta destinado al gasto energético, establecido como razonable. Pero esta aproximación tiene un carácter relativo, y, por tanto, es complicado utilizarla para comparar países con realidades económicas diferentes.

Existen diferentes modelos e índices que buscan dar cuenta de la situación de pobreza energética en el mundo. En su página web, ONU-Energía, el nuevo mecanismo interinstitucional de la ONU en materia energética, da cuenta de dos: el Índice Multidimensional de la Pobreza Energética (MEPI) y el Índice de Desarrollo Energético (IDE). Ambos índices pertenecen a los mecanismos de análisis compuestos. Es decir, el resultado final de aplicar uno u otro es un número entre 0 y 1 , que se calcula usando diferentes variables que representan el valor agregado de una dimensión en base a un modelo subyacente (diferentes sub-indicadores). Observando los resultados puede asegurarse que el MEPI y el IDE son índices complementarios. Así, para los países que el IDE muestra un menor nivel de desarrollo energético, el MEPI identifica una pobreza energética aguda.

El MEPI mide los factores que influyen en la pobreza energética de una persona. Utiliza cinco dimensiones que representan los servicios energéticos básicos (cocina, iluminación, electrodomésticos, entretenimiento/educación y comunicación) y que se componen de seis indicadores: el acceso a combustibles modernos y la contaminación interior para la dimensión relacionada con la cocina; el acceso a la electricidad para la iluminación; la propiedad tanto para los electrodomésticos como para los aparatos de entretenimiento y educación; y la disponibilidad de dispositivos de telecomunicaciones. Una persona se considera «pobre energético» si la combinación de los factores medidos excede el umbral establecido. El MEPI mide el número de pobres energéticos y cuantifica la intensidad de la pobreza energética.

El IDE combina datos de acceso y de consumo energético entre 20022010 según cuatro sub-indicadores ${ }^{46}$ : acceso a electricidad; acceso a combustibles modernos en las cocinas; acceso a energía para servicios públicos; y acceso a energía para servicios productivos. Los dos primeros sub-indicadores son utilizados para calcular el acceso en el sector residencial. Los dos finales dan cuenta del sector comunidad.

46 Estos sub-indicadores utilizan a su vez datos de acceso y de consumo energético. 
En el informe «Energía para Todos», la $\mathrm{AIE}^{47}$ intenta calcular las implicaciones que el acceso universal a la energía en 2030 tendría en diferentes elementos del sistema energético actual (comparados con su principal escenario de análisis, el de «Nuevas Políticas»). El acceso universal a la electricidad supondría, además de un aumento en la demanda total de energía y de las emisiones de $\mathrm{CO}_{2}$, un incremento en la inversión media anual de entre 30.000 y 35.000 millones de dólares durante el periodo 2010-2030, es decir, alrededor de un 3\% de la inversión global anual realizada por el propio sector. Sin embargo, en 2010, la inversión fue de 9.000 millones de dólares ${ }^{48}$. La inversión está en manos tanto de entes privados como públicos sin embargo, no siempre es posible encontrar un marco en el cual los intereses de ambos coincidan. Durante un tiempo, la estrategia seguida por el Banco Mundial estaba marcada por los objetivos de un proyecto neoliberal. Se centraba en una reforma estructural que favoreciera la participación privada y el mercado. Con el tiempo, esta estrategia se ha ido adaptando hasta organizarse alrededor de dos objetivos básicos: el acceso seguro y fiable y la transición a un sistema energético más limpio ${ }^{49}$. Los inversores privados con frecuencia priorizan proyectos e infraestructuras con beneficios asegurados mientras descuidan proyectos de distribución descentralizada (off grid) y los mercados de bajos ingresos, ya que el nivel de riesgo es mayor, por lo que la rentabilidad, además de ser a largo plazo, es incierta ${ }^{50}$. La baja densidad de clientes en zonas rurales puede aumentar los costes de proveer el servicio al tiempo que hace más difícil y costoso el cobro por el mismo, lo que desanima la participación privada. Por su parte, los actores públicos, no siempre tienen las capacidades necesarias para llevar a cabo estos proyectos o no los encuentran suficientemente atractivos en número de votos, por lo que dan prioridad a otras necesidades y demandas ${ }^{51}$.

Pero las barreras al acceso universal a la energía no sólo son de carácter económico o financiero. No todas las inversiones necesarias para evitar los efectos de la pobreza energética necesitan la construcción de grandes

47 International Energy Agency (IEA), World Energy Outlook 2011, IEA, 2011, pp. 668.

48 Ibidem.

49 Dubash. N. K. y Florint, A., loc. cit., p. 9.

50 Wilson, E.; RAI, N. and BeST, S., «Sharing the Load: Public and Private Sector Roles in Financing Pro-Poor Energy Access», IIED, London, 2014.

51 Sovacool, B. K., «The Political Economy of Energy Poverty: A Review of Key Challenges», Energy for Sustainable Development, vol. 16, n 3, 9 (2012), pp. 278-279. 
y costosas infraestructuras o grandes desembolsos ya que se podrían implantar programas de micro financiación y/o cofinanciación ${ }^{52}$. Las barreras también pueden ser de naturaleza tecnológica, política y socio-cultural. B. K. Sovacool ${ }^{53}$ ofrece algunos ejemplos. Por ejemplo, el autor expone cómo algunas religiones o culturas rechazan el uso de biogás derivado de algunos animales considerados impuros. En otras ocasiones, es el desconocimiento o la falta de información suficiente sobre una tecnología en particular lo que incrementa el temor a utilizarla. Los programas que eduquen en el correcto uso de la biomasa en el hogar pueden ser de gran utilidad para reducir los daños en salud. Por último, también alude a la falta de personal cualificado, la mala o insuficiente planificación de los proyectos, las políticas cambiantes o la corrupción.

\section{La energía y el clima}

Hasta no hace mucho tiempo, el cambio climático se consideraba como un elemento prescindible de la agenda internacional, confinado en el área de la política medioambiental. En la actualidad, sin embargo, el cambio climático es una de las grandes preocupaciones en todos los niveles y todos los ámbitos $^{54}$. Enfrentarse al cambio climático implica cambios significativos en las conductas de consumo a nivel mundial. También afecta a la preferencia de unas fuentes sobre otras, lo que influye en el precio de las mismas ${ }^{55}$.

Pero el camino que hubo de recorrerse hasta llegar a la Conferencia de las Naciones Unidas sobre el Medio Ambiente y el Desarrollo celebrada en Río en 1992, testigo de la aprobación de la Convención sobre el Cambio Climático y preliminar de la firma del Protocolo de Kioto en 1997, fue un camino largo que comenzó más de dos siglos antes con la obsesión de varios científicos por los glaciares y el misterio de la Edad de Hielo ${ }^{56}$.

52 GonZález-Eguino, M., «La pobreza energética y sus implicaciones», 2014.

53 Sovacool, B. K., «The Political Economy of Energy Poverty...», loc. cit.

54 Para profundizar en la evolución de las políticas sobre el clima véase O. Costa, «Los regímenes internacionales del medio ambiente y las potencias emergentes. La provisión multilateral de bienes públicos durante la transición de poder», en BouZa Vidal, N.; García SEgura, C.; Rodrigo Hernández (dir.), A. J. y PAREJA, P. (coord.), La gobernanza del interés público global, Tecnos, Madrid, 2015, pp. 313-332.

55 SHAFFER, B., op. cit., p. 105.

56 Yergin, D., The Quest..., op. cit., p. 474. 
a) Aproximación al concepto de cambio climático

El cambio climático es consecuencia de la excesiva acumulación de los llamados gases de efecto invernadero (GEI), principalmente de $\mathrm{CO}_{2}$, en la atmósfera. La importancia de mantener unos niveles adecuados de estos gases -dióxido de carbono $\left(\mathrm{CO}_{2}\right)$, metano $\left(\mathrm{CH}_{4}\right)$, óxidos de nitrógeno $\left(\mathrm{NO}_{\mathrm{x}}\right)$, ozono $\left(\mathrm{O}_{3}\right)$, clorofluorocarbonos (CFC) y vapor de agua- se debe a su capacidad de captura y almacenamiento de parte de los rayos solares (rayos ultravioletas) que la tierra rebota al espacio en forma de calor (rayos infrarrojos). De esa forma se evita una bajada drástica de la temperatura terrestre (a niveles de congelación) durante las horas nocturnas y se mantiene una temperatura media a lo largo de todo el día necesaria para el desarrollo óptimo de la vida tal y como la entendemos. Un cambio en la concentración, bien por exceso (retendrían demasiado calor) como por defecto (el calor retenido no sería suficiente), tendría, por tanto, una consecuencia directa en la temperatura de la Tierra y en su condición de planeta habitable.

El cambio climático es el responsable del calentamiento global, del aumento del nivel de los mares y de la erosión costera, de los cambios en los ciclos de lluvia aumentando las precipitaciones en las latitudes altas y disminuyendo en el subtrópico e intensificando las tormentas tropicales, de la disminución de la cantidad de nieve y de hielo, de fenómenos climatológicos extremos más intensos y más frecuentes, y de la aparición de microclimas cambiantes que afectan a la producción de alimentos y a la habitabilidad de ciertas zonas ${ }^{57}$. Abarca, por tanto, diferentes efectos relacionados con el clima, es decir, con las pautas de comportamiento a lo largo del tiempo del tiempo atmosférico. Sin embargo, hasta no hace mucho se consideraba que el único, o principal, efecto era el denominado «calentamiento global», una elevación en la temperatura terrestre que, en su día, se consideró un efecto positivo.

Los estudios empíricos sobre el cambio climático tuvieron su origen a finales del siglo XVIII, cuando el profesor Horace Bénédict de Saussure construyó su hot box, una especie de mini invernadero, con la esperanza de averiguar por qué la Tierra no se congelaba en las horas nocturnas. Este trabajo le llevó a la conclusión de que la atmósfera actuaba como una «tapa» que impedía la

57 Brown, M. A. y Sovacool, B. K., Climate Change and Global Energy Security: Technology and Policy Options, MIT Press, 2011, pp. 56-58; Solá PARdell, O., «Desplazados medioambientales: una nueva realidad», Cuadernos Deusto de Derechos Humanos, nº 66 (2012), p. 20. 
salida del calor. Ese fue el origen del concepto de «efecto invernadero». El respaldo matemático a esta teoría se la daría, en 1820, el matemático francés Joseph Fourier. El siguiente paso se debe al científico suizo Louis Agassiz, quien en su obsesión por estudiar los glaciares, estableció en 1837 una teoría verdaderamente revolucionaria: la existencia de una era, en términos de temperatura, anterior a la actual, dando origen al concepto de clima.

El trabajo de estos científicos sirvió de base a John Tyndal para establecer la relación entre los dos conceptos, es decir, cómo el efecto invernadero de la atmósfera podía causar un cambio en el clima. Tras su muerte en 1894, el químico sueco Svante Arrhenius demostró que una disminución en la concentración de $\mathrm{CO}_{2}$ a la mitad supondría una disminución en la temperatura de entre 4 y $5^{\circ} \mathrm{C}$. De igual forma si la cantidad de este gas se doblaba, la temperatura podría aumentar entre 5 y $6^{\circ} \mathrm{C}$. Aunque, a diferencia de hoy, este calentamiento se consideró beneficioso para la humanidad, ya que un clima más benigno en ciertas áreas mejoraría la producción agrícola y facilitaría las condiciones de vida ${ }^{58}$. Durante las siguientes décadas la industrialización floreció y con ella las emisiones de $\mathrm{CO}_{2}$, sin que nadie prestara atención a su efecto en el clima. O casi nadie. Sólo un meteorólogo, Guy Stewart Callendar, aficionado pero minucioso en su trabajo, continuó con los estudios que evidenciaban el cambio climático, aunque también desde una aproximación positiva a tal efecto. No fue hasta pasado medio siglo XX cuando las implicaciones del aumento de GEI en la atmósfera adquirieron un sentido negativo.

El trabajo sobre el tiempo atmosférico realizado por el International Geophysical Year (IGY), pero sobre todo el trabajo de medición y predicción de la concentración de $\mathrm{CO}_{2}$ en la atmósfera realizado por Charles David Keeling, padre de la curva que tomó su nombre, supusieron un punto de inflexión. Keeling demostró cómo en apenas medio siglo, la atmósfera había pasado de tener 315 partes por millón de $\mathrm{CO}_{2}$ a 394 partes por millón. El cambio climático atrajo la atención no sólo del mundo científico y académico, sino también del político.

El nivel de crecimiento de las emisiones actuales de $\mathrm{CO}_{2}$ está acelerándose en vez de disminuir. El objetivo perseguido es limitar la concentración a un máximo de 450 partes por millón para no superar un aumento en la temperatura de $2^{\circ} \mathrm{C}$. El cambio climático está presente en los debates internaciones y, aunque no todo el mundo comparte ni el objetivo ni el diagnóstico, los esfuerzos en

58 Yergin, D., The Quest..., op. cit., p. 434 
este campo tienen una influencia directa en las políticas energéticas en todos los niveles: locales, regionales, nacionales y globales. Sin embargo, la adopción de medidas concretas en ocasiones sólo se traduce en recomendaciones ${ }^{59}$.

b) Implicaciones del cambio climático en las políticas energéticas

A excepción de los clorofluorocarbonos, los GEI no son un producto final de la iniciativa humana. Sin embargo, la acción humana sí influye de forma decisiva en la variación de la concentración de los mismos en la atmósfera $y$, por tanto, en la velocidad a la que se desarrolla ese cambio en el clima. El desarrollo industrial vino acompañado de un fuerte incremento en el consumo energético, especialmente de los combustibles fósiles, que favorece el desarrollo económico y social, lo que a su vez impulsa el consumo de energía, cerrando así un círculo vicioso que se auto alimenta. Las emisiones antropogénicas de GEI aumentaron en más del $80 \%$ entre 1970 y $2010^{60}$ y si la tendencia sigue en aumento será del orden del $130 \%$ en $2040^{61}$.

Hoy en día, la principal fuente de emisiones de $\mathrm{CO}_{2}$ relacionada con la actividad humana es la generación de electricidad. Le siguen la industria; la agricultura, silvicultura y otros usos del suelo (conocido esto como AFOLU por su terminología inglesa) y el transporte ${ }^{62}$. El peso de la electricidad en la economía mundial pone de manifiesto la importancia de la elección de la fuente de energía para satisfacer las necesidades futuras ya que es necesario considerar aspectos como la seguridad (energética y física), la economía, el medio ambiente, el carbono y el cambio climático, los valores y las políticas públicas, y todo sin olvidar el requisito básico de fiabilidad ${ }^{63}$. Aspectos que en ocasiones son difíciles de armonizar. Ese es el caso, según expone Jonathan Symons, entre cambio climático y seguridad energética. Las políticas destinadas a la mitigación del cambio climático ejercen una presión en el precio de la energía contraria al énfasis que la seguridad energética pone en la asequibilidad ${ }^{64}$.

59 Gutiérrez Espada, C.; Bermejo García, R. y López-Jacoiste Díaz, E., «El Documento Final de la Cumbre Mundial 2005», UNISCI Discussion Papers, nº 10 (2006), pp. 135.

60 PaChuri, R. K. et al., Climate Change 2014: Synthesis Report. Contribution of Working Groups I, II and III to the Fifth Assessment Report of the Intergovernmental Panel on Climate Change, 2014.

61 Sovacool, B. K., «An International Comparison of Four Polycentric Approaches to Climate and Energy Governance», Energy Policy, vol. 39, nº 6 (2011), p. 3834.

62 PAChURI, R. K. et al., loc. cit.

63 Yergin, D., The Quest..., op. cit., p. 399.

64 AnCESCHI, L. y J. Symons, J., Energy Security in the Era of Climate Change: The Asia-Pacific Experience, Palgrave Macmillan, 2011, p. 2. 
La elección final de las fuentes que componen la matriz energética se realiza determinada por las limitaciones y las ventajas de la región, pero también por la tecnología, la economía, la disponibilidad de los recursos y por las tres «Pes»: política, políticas y opinión pública ${ }^{65}$. Según las proyecciones a medio y largo plazo de diversas organizaciones internacionales, los combustibles fósiles -petróleo, gas y carbón- seguirán ocupando los primeros puestos en la lista de fuentes de energía utilizadas, aunque perdiendo peso relativo frente a las renovables. En 2012, según datos ofrecidos por la Agencia Internacional de la Energía (AIE) en su Escenario de Nuevas Políticas (ENP), alrededor del $41 \%$ de la electricidad mundial se generaba usando carbón. Casi el mismo porcentaje que de gas (22\%) y renovables $(21 \%)$ juntas. El 16\% restante se debía a la energía nuclear (11\%) y al petróleo (5\%). Para 2040, esos porcentajes se habrán convertido en el 31\%, 24\%, 33\%, $12 \%$ y $1 \%$ respectivamente ${ }^{66}$.

El carbón es la principal fuente de energía para satisfacer la demanda mundial de electricidad. $\mathrm{Y}$ aunque las predicciones son a la baja, su peso todavía será importante dentro de un cuarto de siglo debido, principalmente, al alto consumo de este recurso entre los países en vías de desarrollo. La amplia distribución geográfica lo convierte en una fuente segura y relativamente barata. Si bien, es altamente contaminante. Del total de $\mathrm{CO}_{2}$ emitido en 2012 en la generación de electricidad, según el cálculo de la AIE para su ENP, el 72\% correspondió al carbón. En 2040 seguirá siendo el 71\%. Sería necesario moverse al escenario de los 450 para que esta cifra se redujera al 38\%. Claro que este cambio implica una reducción en la generación eléctrica a partir de carbón igual a 18 puntos respecto al $\mathrm{ENP}^{67}$. La mejor respuesta tecnológica desarrollada hasta el momento en el intento de encontrar una solución que permita combinar las ventajas e inconvenientes de usar carbón en la generación de electricidad es la técnica de captura y almacenamiento del carbono (más conocida como CCS por su nomenclatura inglesa). Esta técnica consiste en almacenar ese carbono bajo el suelo terrestre. Pero la tecnología es muy cara y, para que realmente fuese suficiente a nivel global, se debería crear una industria de CCS similar en tamaño a la industria energética total existente. Esto, además de los retos obvios en inversión y tiempo, también implicaría

65 Yergin, D., The Quest..., op. cit., p. 403.

66 International Energy Agency (IEA), World Energy Outlook 2014..., op. cit., p. 608.

67 Ibid., pp. 608-609. 
responder a todo tipo de cuestiones políticas y legales al tiempo que encarecería el precio del carbón ${ }^{68}$.

La utilización de gas en la generación de electricidad es atractiva por varias razones: es una tecnología segura y económicamente viable; es una fuente de energía muy flexible; y es fácil adaptar la producción de la planta a la demanda del momento. En el contexto del cambio climático, el gas también destaca, comparado con otros combustibles fósiles, por su menor emisión de GEI. La aparición del gas no convencional (sobre todo del gas de esquisto) alentó la idea de un gas abundante y a un precio relativamente bajo. Las proyecciones a medio y largo plazo le auguran un peso importante en la matriz energética mundial y en la producción de electricidad. Sin embargo, también tiene sus inconvenientes. En primer lugar, el gas no es una fuente totalmente limpia, por lo que en un futuro, más o menos lejano, puede estar sometido a las mismas presiones de mitigación que el carbón ahora. En segundo lugar, no están claros los posibles riesgos de contaminación asociados a la técnica de explotación del gas no convencional, por lo que no ha superado la barrera de la oposición social.

Una fuente alternativa al carbón (o a cualquier combustible fósil) en la generación de electricidad es la energía nuclear. Su principal ventaja es que es una fuente limpia, es decir, no emite $\mathrm{CO}_{2}$. Sin embargo, la preocupación por un posible accidente nuclear como los ocurridos en Chernóbil (1986) y Fukushima (2011) y la gestión de los residuos radioactivos -iodo, cesio y estroncio- son dos razones de peso para que gran parte de la población y algunos gobiernos frenen su desarrollo. También lo es la preocupación de que la tecnología nuclear pueda ser utilizada para otros fines no civiles por ciertos gobiernos o grupos terroristas.

En cuanto a las energías renovables, aunque la tendencia en su uso tiene signo positivo, todavía están lejos de suponer una solución real a la hora de cubrir la demanda eléctrica. En la actualidad, son responsables de producir algo más de una quinta parte de la electricidad global (igual que el gas). Además, existen varios factores que afectan negativamente a su desarrollo como son las incertidumbres políticas, los retos económicos, las reducciones en los incentivos y la competencia de otras fuentes de energía y las dificultades que experimentan algunos países y regiones al tratar de incluir las renovables en sus redes eléctricas.

68 Yergin, D., The Quest..., op. cit., pp. 403-406. 
El desarrollo de los países más desfavorecidos, normalmente acompañado de un incremento del consumo basado en recursos fósiles, plantea el problema de cómo compatibilizar el desarrollo económico, el desarrollo social y la protección ambiental ${ }^{69}$. Todos los países del mundo tienen derecho a desarrollarse económicamente y alcanzar mejores niveles de vida, lo cual a priori implica un consumo energético por habitante mayor. Sin embargo, ese aumento del bienestar económico no puede seguir el modelo utilizado por los países industrializados porque traería consigo la destrucción de los ecosistemas y de los recursos del planeta, hecho que a su vez se erigiría en una traba al desarrollo. La salida de esta difícil situación requiere un esfuerzo tecnológico que extienda y abarate la diversificación energética hacia el aprovechamiento de fuentes limpias o menos contaminantes, así como una política de alcance global capaz de reconciliar los intereses opuestos no sólo de productores y consumidores, sino también de países con un alto y con un bajo consumo energético per cápita. El Protocolo de Kyoto, vinculado al tratado de La Convención Marco sobre el Cambio Climático ha sido, hasta el momento, el principal acuerdo internacional con efecto en aspectos esenciales de la estructura jurídico-políticaeconómica de un país a nivel local, comunitario e internacional ${ }^{70}$. A finales de 2015 se celebró en París la Conferencia sobre el Clima (COP-21) donde se llegó a un nuevo acuerdo internacional.

La energía históricamente ha formado parte de la high politic, vinculada a los intereses particulares de los Estados, sin embargo, el repaso a los tres pilares de la gobernanza global energética ha demostrado que los retos energéticos han superado las barreras nacionales. Se precisa de una aproximación común y de cooperación entre los diferentes actores.

\section{LAS INSTITUCIONES DE LA GOBERNANZA ENERGÉTICA GLOBAL}

El proceso de la gobernanza global a menudo se identifica con el desarrollo institucional destinado a coordinar actividades que traspasan las fronteras nacionales. La expectación sobre el papel de las organizaciones internaciona-

69 Loperena Rota, D., «El derecho al desarrollo sostenible», en EmbiD Irujo, A. (dir.), El derecho a un medio ambiente adecuado, Iustel, Madrid, 2008, p. 73; Para profundizar en estos tres conceptos véase LOPERENA Rota, D., «Hacia un concepto útil de desarrollo sostenible», IeZ: Ingurugiroa eta zuzenbidea $=$ Ambiente y derecho, $\mathrm{n}^{\circ} 1$ (2003), p. 33-45.

70 IbARRa SARLAT, R., «El Mecanismo de Desarrollo Limpio. Estudio crítico de su régimen jurídico a la luz del imperativo de sostenibilidad», Revista Aranzadi de Derecho Ambiental, nº 20 (2012), p. 39. 
les tras el final de la Guerra Fría es una de las fuentes más importantes en el desarrollo de la teoría de la gobernanza global ${ }^{71}$. Sin embargo, como apunta Wilkinson ${ }^{72}$, pensar en los dos procesos como sinónimos es un error ya que ambos se diferencian, como mínimo, en dos grandes aspectos. Primero, porque la gobernanza global está compuesta por un amplio número de actores, entre los que se encuentran las organizaciones intergubernamentales. Segundo, porque esta variedad de actores interactúa cada vez más para gestionar un catálogo creciente de asuntos políticos, económicos y sociales ${ }^{73}$.

En el ámbito energético, la aceptación de la tesis propuesta por C. Frei ${ }^{74}$ de que la energía es un bien público global y por tanto requiere de la intervención de una institución global alimenta el debate abierto sobre quién gobierna o debería gobernar la energía global: ¿debería una única institución hacer frente a los desafíos de la energía global o sería mejor mantener una estructura plural? ${ }^{75}$

\section{Las cuatro tendencias institucionales para la gobernanza energética global}

Una de las características más notables de la evolución de las instituciones internacionales energéticas es la rapidez con la que se han creado y evolucionado. Al final de la Segunda Guerra Mundial, la mayoría de las principales organizaciones internacionales actuales ni siquiera existían. Y las que lo hacían tenían un presupuesto y un número de miembros limitados ${ }^{76}$. Una excepción a esta regla en el ámbito energético fue el Consejo Mundial de la Energía. Creado en 1923 en el periodo de entreguerras, su primera conferencia contó con 1.700 delegados provenientes de 40 países.

71 Hewson, M. y Sinclair, T. J., «The Emerge of Global Governance Theory», en M. Hewson and T. J. Sinclair (eds.), Approaches to Global Governance Theory, Albany, State University of New York, 1999, p. 13.

72 Wilkinson, R. y Hughes, S., «Global Governance: A Preliminary Interrogation», en R. Wilkinson and S. Hughes (eds.), Global Governance: Critical Perspectives, Routledge, New York, 2002.

73 Rosenau, J. N. y Czempiel, E. O., Governance without Government: Order and Change in World Politics, vol. 20, Cambridge University Press, 1992, pp. 311.

74 FreI, C., «Dossier Energy: Blueprint for a Global Energy Authority», Europe's World: Policy Dossier, 2007.

75 Afectan a los principales actores de dicha gobernanza como la fragmentación y la legitimidad véase Bouza Vidal, N.; García Segura, C.; Rodrigo Hernández (dir.), A. J. y Pareja, P. (coord.), op. cit.

76 Luard, E. y Contin, A., Organismos Internacionales: El Marco Naciente De La Interdependencia, El Manual Moderno, 1979, p. 330. 
En la actualidad se distinguen cuatro tendencias institucionales en el ámbito de la gobernanza energética global ${ }^{77}$. La primera tendencia revela la existencia de unas instituciones especializadas que fueron creadas en determinados momentos claves de la historia energética de la segunda mitad del siglo XX como la OPEP, la AIE y el Tratado de la Carta de la Energía. Un contexto histórico que coincidió con la expansión de la tesis de la evolución de los regímenes internacionales ${ }^{78}$ y cooperación de Keohane. Según esta reflexión, la aparición de la OPEP y de la AIE obedeció a unas lógicas no jerárquicas de cooperación y de oposición de bloques originando dos «regímenes»-de producción y de seguridad- que permitirían reducir los costos gracias a la cooperación, el intercambio de información y la construcción de reglas prácticas. No se esperaba que estas organizaciones se encargasen de hacer cumplir estas reglas ${ }^{79}$.

La segunda tendencia consiste en la inclusión de cuestiones energéticas en las agendas y mandatos de instituciones internacionales ya existentes. Es el caso de la OMC, de las instituciones de Bretton Woods, del G8 sobre todo desde la cumbre de Gleneagles, de la OTAN y de las Naciones Unidas a través de la creación de ONU-Energía. La aparición de problemas nuevos y la aceptación de que muchas de las cuestiones más difíciles de solventar sólo podrían hacerse desde bases internacionales impulsó que instituciones ya consolidadas en la esfera internacional decidiesen intervenir en el proceso.

La tercera tendencia se basa en que cada vez se constituyen más organizaciones especializadas que pretenden responder a desafíos concretos. Se trata de arreglos institucionales específicos, algunos dependientes directos de las anteriores, para, por ejemplo, luchar contra el cambio climático, promover las energías renovables y la eficiencia energética. Ejemplos de esta tendencia son IRENA, la red REN21 (Renewable Energy Policy Network for the 21st Century), la Sociedad de Energía Renovable y Eficiencia Energética (REEP) o la Asociación Internacional de Cooperación para la Eficiencia Energética (IPEEC).

77 KÉRÉBEL, C., «Pour Une Gouvernance Mondiale De L'Énergie Renforcée», La Gouvernance Mondiale De L'énergie, 2009.

78 La definición de «régimen internacional» más aceptada es la de S. Krasner (1983) que lo define como «los principios, normas, reglas y procedimientos de toma de decisión, implícitos o explícitos, alrededor de los que convergen las expectativas de los actores en un área determinada de las relaciones internacionales». KRASNER, S., «Structural Causes and Regime Consequences: Regimes as Intervening Variables» en ID. (ed.), International Regimes, Cornell University Press, 1983, p.2.

79 Keohane, R. O., Después De La Hegemonía, Cooperación Y Discordia En La Política Económica Mundial, Grupo editor latinoamericano, 1988, pp. 275-276. 
Por último, la cuarta tendencia la protagonizan los analistas que propugnan la creación de una única organización mundial de la energía, que represente a todos los actores en el juego energético. Esta cuarta tendencia, opuesta a las tres anteriores, ha generado el debate sobre qué sistema de gobernanza energética sería más conveniente: un sistema centralizado o un sistema plural.

\section{Centralidad vs. Pluralidad}

En 1956, el entonces presidente del CME, Sir Harold Hartley, se mostraba partidario de un sistema centralizado. En su discurso de apertura de la $5^{\text {a }}$ Conferencia Mundial de la Energía recordaba a los allí presentes cómo el fundador de la institución, Daniel Dunlop, había tenido la capacidad, treinta años antes, de ver la necesidad de un foro que representase a todos los sectores relacionados con la energía y en el que pudieran discutir los problemas de interés común para que las políticas energéticas futuras fueran formuladas desde una perspectiva amplia ${ }^{80}$. Años más tarde, en 2008, el antiguo director general de la Agencia Internacional de la Energía Atómica (AIEA), Mohamed El-Baradei, recomendaba la creación de una institución global para hacer frente a la crisis energética. Otros expertos eran partidarios de una cooperación internacional más informal, basada en un diálogo en torno a intereses compartidos y que incluyera a diferentes actores de la energía y del comercio $^{81}$.

Todos los expertos coinciden en que los sistemas energéticos y los retos a los que deben enfrentarse son complejos y que las soluciones pasan por una larga y profunda transformación de los mismos. Las conexiones entre los diferentes sistemas energéticos nacionales así como las relaciones entre estos y los sectores tecnológicos, operacionales y no energéticos se verán afectadas. Es preciso, por tanto, una actuación simultánea y no secuencial ${ }^{82}$. La característica clave es la complejidad. Además, las instituciones globales actuales fueron creadas en la segunda mitad del siglo xx y desde entonces el equilibrio global del poder ha cambiado y seguirá cambiando significativamente a medida que China, India y otras economías de mercado emergentes vayan logrando cierto

\footnotetext{
80 «The Fifth World Power Conference», fournal I.E.E.E., 1956, p. 513.

81 KéréBel, C., «Qu'est-Ce Que...», loc. cit., p. 15.

82 Cherp, A.; Jewell, J. y Goldthau, A., loc. cit., pp. 77-79
} 
poder económico. El sistema internacional de instituciones tal y como se creó no es el adecuado para hacer frente a los desafíos y tareas del siglo $\mathrm{XXI}^{83}$.

Quienes defienden una única institución basan sus argumentos en que hoy no existe una institución internacional que pueda liderar el proceso necesario para enfrentarse a los desafíos planteados por la gobernanza de la energía a nivel global. Ven la complejidad del sistema como un problema, critican la fragmentación y la falta de coordinación y promulgan la concentración de todas las funciones en una sola institución ${ }^{84}$. Según S. De Jong, la arquitectura actual de la energía mundial es un puzle mal ajustado al cual le faltan piezas. Hay numerosas organizaciones e instituciones con características muy diferentes que desempeñan algún tipo de papel en la energía global pero ninguna es capaz, debido a sus características, de hacer frente a los desafíos actuales. Para que haya una gobernanza energética global efectiva haría falta una organización con una institución capaz de hacer cumplir sus normas de manera más estricta aunque sería a coste de su representatividad ${ }^{85}$.

Dentro de los autores que apoyan un sistema plural encontramos a $\mathrm{F}$. Biermann, P. Pattberg, H. van Asselt y F. Zelli ${ }^{86}$. Estos autores utilizan el concepto de «arquitectura de la gobernanza global» para describir un modelo situado entre el concepto de orden internacional -el cual abarcaría todo el conjunto en su totalidad-y el concepto de régimen internacional -mucho más limitado en su alcance-. El concepto de estructura de la gobernanza global tendría un alcance intermedio, pudiendo integrar varios regímenes internacionales que actúan en un área temática de las que se compone el orden internacional. Estas áreas se caracterizan por la participación de un mosaico de instituciones internacionales que son diferentes en su carácter (organizaciones, regímenes y normas implícitas), en sus circunscripciones (públicos y privados), en su ámbito espacial (desde bilateral a lo global), y en su objeto (desde ámbitos políticos específicos a las preocupaciones universales). $\mathrm{Y}$ es por esto que los autores hablan de una estructura fragmentada. Si bien, también dentro de

83 BRAdFord, C. I. y LinN, J. F., Global Governance Reform: Breaking the Stalemate, Brookings Institution Press, 2007, p. 1; EsCRIBANO, G., «Fragmented Energy Governance and the Provision of Global Public Goods», Global Policy, vol. 6, n 2 (2015), p. 97.

84 Cherp, A.; Jewell, J. y GoldThau, A., loc. cit., p. 85

85 Jong, S. DE, «Vers Une Gouvernance Mondiale De Lénergie: Comment Compléter Le Puzzle», International Development Policy| Revue Internationale De Politique De Développement, $\mathrm{n}^{\circ} 2$ (2011).

86 Biermann, F. et al., «The Fragmentation of Global Governance Architectures: A Framework for Analysis», Global Environmental Politics, vol. 9, nº 4 (2009), pp. 14-40 
esta fragmentación hay quienes abogan por reducirla al mínimo, mediante la creación de una institución que domine un campo temático, y quienes defienden las virtudes de la fragmentación total.

A. Cherp, J. Jewell y A. Goldthau ${ }^{87}$ ven las semillas de un sistema plural al diferenciar los tres ámbitos de la gobernanza energética global: la seguridad energética, el acceso a la energía y el cambio climático. Para ellos, la reforma de la gobernanza energética global para una acción exitosa frente a los tres desafíos implica una mayor interrelación de los mismos a la vez que se preservan las características únicas e importantes de cada uno. Otros autores consideran suficiente evidencia la participación activa de distintos agentes y redes para defender la necesidad de que sea un grupo de instituciones maduras (incluyendo la ONU y todas sus agencias especializadas) el que coordine y regule los comportamientos transnacionales y globales. Según R. O. Keohane, «la construcción de instituciones es un asunto difícil y frustrante» por lo que más importante que crear otras nuevas es «procurar mantener las instituciones internacionales valiosas existentes, ya que el esfuerzo requerido para ello es menor del que haría falta para construir otras nuevas» ${ }^{88}$.

\section{REFLEXIONES FINALES}

La «gobernanza energética global» es un ámbito de investigación en pleno desarrollo que ha surgido recientemente como un ámbito específico dentro del campo de estudios de la gobernanza global. Un concepto que, aunque todavía está en proceso de construcción, los elementos comunes de las diferentes definiciones que los expertos ofrecen, tanto sobre gobernanza en general -procesos, sistemas, actores, problemas colectivos, normas- como los específicos de la gobernanza energética -recursos y servicios energéticos-, justifican el planteamiento de los tres grandes interrogantes (qué se debe gestionar, quién lo debe gestionar y cómo se debe gestionar) que, a nuestro juicio, deben analizarse para entender y elaborar un plan de acción que logre el objetivo internacional de un modelo energético seguro, asequible y respetuoso con el medioambiente. En este texto hemos abordado el qué y, en menor medida, el quién.

87 Cherp, A.; Jewell, J. y Goldthau, A., loc. cit., p. 75

88 Keohane, R. O., op. cit., p. 315. 
Nadie pone en duda la importancia de la energía para el desarrollo social y el crecimiento económico de las sociedades. Quizá por ello la energía siempre ha sido considerada como un elemento de la política interna de los Estados y existe, todavía en la actualidad, esa reticencia a ceder parte de la soberanía estatal en este ámbito, a pesar del reconocimiento de la extrema necesidad de elaborar planes de acción integradores, en los que participen todos los actores.

Diferentes autores exponen la evolución de la agenda internacional con la incorporación de cuestiones alejadas de la seguridad, entendida en su concepción tradicional, y la estrecha relación que todas y cada una de ellas mantiene con la energía. Según los criterios de clasificación utilizados obtendremos un número mayor o menor de ámbitos, más o menos específicos, que deben atenderse. En la actualidad se apunta a tres ejes principales: la seguridad energética, la pobreza energética y el cambio climático. Aunque es necesario analizar y comprender los principales actores, problemas, intereses, riesgos y posibles soluciones de cada uno de ellos, la postura de mantener una aproximación individualizada y separada defendida por algunos expertos es, a nuestro juicio, una aproximación errónea. En un nivel de análisis inferior, se observa que todos ellos comparten elementos como el precio o el acceso a las diferentes fuentes de energía y a la tecnología (entre otros) y, que si no se considera esta realidad al discurrir posibles políticas, medidas o pautas de actuación, los efectos positivos en un ámbito pueden ser superados por los efectos negativos en otro.

Quizá el ejemplo más claro de esta interrelación es el cambio climático. Unas políticas destinadas a garantizar la seguridad de suministro y el acceso a la energía mediante la utilización de los recursos fósiles disponibles dentro de los Estados pueden, si no se acompañan de la tecnología necesaria, generar un aumento de los gases de efecto invernadero, agravando el problema del cambio climático, con los riesgos y consecuencias que ello conlleva. Por otra parte, la adopción de medidas que prioricen la lucha contra el cambio climático requiere, por lo general, de una considerable inversión en todos los pasos intermedios entre las fuentes primarias y los servicios energéticos que encarece el precio de la energía. El qué, por tanto, es extremadamente complejo. Las políticas necesarias deben tener en cuenta múltiples elementos. La aproximación y las prioridades que se establezcan determinarán el proceso. Pero las prioridades las establecen los agentes, el quién. Y, como se ha expuesto, no existe un consenso sobre esta cuestión.

El sistema internacional actual es un sistema multipolar y multinivel, en el que, a pesar del gran desarrollo que ha experimentado la cooperación in- 
ternacional, los Estados siguen defendiendo su soberanía y su independencia a la hora de tomar decisiones y participar en los procesos internacionales, de acuerdo con sus propios intereses. Y el ámbito energético no es una excepción. La seguridad y el desarrollo económico ocupan puestos importantes en la lista de prioridades, por lo que también prevalecerán en las políticas energéticas.

Es preciso resaltar, sin embargo, el creciente peso que la preocupación por el cambio climático está experimentando. La interiorización de que las consecuencias del cambio climático no se limitan sólo a un cambio de temperatura o a regiones del mundo que ya soportan unas condiciones climáticas extremas sino que tendrán su reflejo en todos los Estados y en todos sus ámbitos, incluyendo los de seguridad nacional y desarrollo económico y social, está modificando la postura de algunos de los Estados más reticentes y delineando el marco integrador de las diferentes políticas energéticas. Así lo constata la firma por 195 Estados del texto acordado en la última Convención Marco de las Naciones Unidas sobre el Cambio Climático (COP 21) celebrada en París a finales de 2015 .

Por otra parte, la resistencia a ceder soberanía en una organización supranacional, también tendrá su impacto en la gobernanza energética global. Desde un plano teórico, se diferencian dos modelos opuestos: un modelo centralizado y un modelo plural. En el primero, el quién de la gobernanza global sería una única organización mundial encargada de gestionar todos los aspectos relacionados con la energía. En el segundo, se defiende la fragmentación tanto de los actores como de sus mandatos. En la actualidad, el primero se percibe como una posibilidad remota si no inalcanzable.

Agradecimientos: Agradezco a Kepa Sodupe (Catedrático de Estudios Internacionales de la UPV/EHU), Ana Fernández (Departamento de Enonometría y Estadística de la UPV/EHU) por su disponibilidad y apoyo. 
